\title{
Semaphorin 4D is a potential biomarker in pediatric leukemia and promotes leukemogenesis by activating PI3K/AKT and ERK signaling pathways
}

\author{
HONGCHAO JIANG ${ }^{1-3^{*}}$, JIAOLIAN TANG $^{4 *}$, LIJUAN QIU ${ }^{1-3,5^{*}}$, ZHEN ZHANG $^{1,3}$, SHULAN SHI $^{1,3}$, \\ LI XUE $^{6}$, LIYUE KUI ${ }^{1,3}$, TILONG HUANG ${ }^{1}$, WEIWEI NAN ${ }^{6}$, BAILING ZHOU ${ }^{1}$, \\ CANCHUN ZHAO $^{1}$, MING $\mathrm{YU}^{7}$ and QIANGMING SUN ${ }^{2,5}$ \\ ${ }^{1}$ Institute of Pediatrics, The Kunming Children's Hospital, Kunming, Yunnan 650228; ${ }^{2}$ Institute of Medical Biology, \\ Chinese Academy of Medical Sciences and Peking Union Medical College, Kunming, Yunnan 650118; \\ ${ }^{3}$ Yunnan Key Laboratory of Children's Major Disease Research, Kunming; ${ }^{4}$ Institute of Pediatrics, \\ Children's Hospital Affiliated to Kunming Medical University, Kunming, Yunnan 650228; ${ }^{5}$ Yunnan Key Laboratory of \\ Vaccine Research and Development on Severe Infectious Diseases, Kunming, Yunnan 650118; ${ }^{6}$ Institute of Medicine, \\ Dali University, Dali, Yunnan 671000; 7 Yunnan Key Laboratory of Stem Cell and Regenerative Medicine, \\ Biomedical Engineering Research Center, Kunming Medical University, Kunming, Yunnan 650500, P.R. China
}

Received September 6, 2020; Accepted December 18, 2020

DOI: $10.3892 /$ or.2021.7952

\begin{abstract}
Semaphorin 4D (Sema4D) is highly expressed in a variety of tumors and is associated with high invasion, poor prognosis and poor therapeutic response. However, the expression and role of Sema4D in leukemia remains unclear. The present study investigated the expression of Sema4D in pediatric leukemia and its effects in leukemia cells. The results demonstrated that Sema4D protein was highly expressed in peripheral blood mononuclear cells of patients with pediatric leukemia, and high levels of soluble Sema4D were also observed in the plasma of these patients. Sema4D knockdown induced cell cycle arrest in $G_{0} / G_{1}$ phase, inhibited proliferation and promoted apoptosis in BALL-1 cells, while Sema4D overexpression exhibited the opposite effect. In Jurkat cells,
\end{abstract}

Correspondence to: Dr Ming Yu, Yunnan Key Laboratory of Stem Cell and Regenerative Medicine, Biomedical Engineering Research Center, Kunming Medical University, 1168 Chunrong Western Road, Kunming, Yunnan 650500, P.R. China

E-mail: yuming@kmmu.edu.cn

Professor Qiangming Sun, Institute of Medical Biology, Chinese Academy of Medical Sciences and Peking Union Medical College, 935 Jiaoling Road, Kunming, Yunnan 650118, P.R. China

E-mail: sunqiangming1972@yahoo.com

${ }^{*}$ Contributed equally

Abbreviations: Sema4D, semaphorin 4D; ALL, acute lymphoblastic leukemia; AML, acute myeloid leukemia

Key words: SEMA4D, biomarker, PI3K, ERK, leukemia
Sema4D knockdown inhibited proliferation and promoted apoptosis, while Sema4D overexpression decreased the abundance of the cells in the $G_{0} / G_{1}$ phase of the cell cycle and promoted proliferation. Sema4D overexpression also increased the migratory capacity of Jurkat cells and the invasive capacity of BALL-1 cells. The phosphorylation level of PI3K was decreased in both Sema4D knocked-down Jurkat and BALL-1 cells, and the phosphorylation level of ERK was decreased in Sema4D knocked-down BALL-1 cells. The phosphorylation levels of PI3K, ERK and AKT were elevated in patients with pediatric leukemia, and were correlated to the increased Sema4D expression. Sema4D overexpression was associated with a shorter overall survival in patients with acute myeloid leukemia. Overall, the results of the present study indicated that Sema4D serves an important role in leukemia development by activating PI3K/AKT and ERK signaling, and it may be used as a potential target for the diagnosis and treatment of leukemia.

\section{Introduction}

Axon-directing factor semaphorin 4D (Sema4D; also called CD100), which was first discovered in the immune system in 1992 (1), is an important member of the IV subfamily of the semaphorin superfamily. It exists in membrane-bound and soluble forms. Soluble Sema4D is produced by proteolytic cleaving of the Sema4D exodomain and is released into the circulation, where it can bind and activate various receptors, such as CD40, CD72 and Plexin-B1 (2). Membrane Sema4D interacts with calmodulin via its $\mathrm{C}$-terminal domain, and the dissociation of this interaction induces its cleavage and release of soluble Sema4D (3), which can be promoted by the stimulator of interferon genes protein (4). Sema4D has been indicated to be involved in the regulation of the immune response in resting 
$\mathrm{T}$ cells and participate in the activation of B lymphocytes and the activation and maturation of antigen-presenting cells via the low affinity receptor CD72 (5). It has also been reported to be associated with the activation of neutrophils and dendritic cells $(6,7)$, and promote eosinophil migration (8).

Sema4D is highly expressed in prostate, colon, oral, lung, pancreatic, breast and ovarian cancer, head and neck squamous cell carcinoma and soft tissue sarcoma compared with healthy tissues, and is involved in angiogenesis and invasion and migration of tumor cells (9-20). Tumors overexpressing Sema4D have been indicated to be highly invasive with a poor prognosis and therapeutic response $(10,12-16,21,22)$. In chronic lymphocytic leukemia (CLL) cells, Sema4D has been indicated to sustain viability and enhance proliferation (23). The interaction of Sema4D with Plexin-B1 has been revealed to promote survival and growth and inhibit apoptosis in B-CLL cells (24). Soluble Sema4D has been demonstrated to enhance the metastasis of head and neck squamous cell carcinoma by interacting with its receptor Plexin-B1, resulting in epithelial-mesenchymal transition (25). A previous study utilizing a murine carcinoma model has indicated that antibodies against Sema4D induced an immune response in tumors via the activation of CD8 T lymphocytes (26). Although antibodies against Sema4D decrease proliferation, they have also been reported to enhance invasion and metastasis in a pancreatic neuroendocrine cancer mouse model and patients with pancreatic neuroendocrine cancer (27).

Acute lymphoblastic leukemia (ALL), which affects 80-90 children per million annually in Italy (28), accounts for $\sim 25 \%$ of childhood cancer deaths, representing the most common malignancy in children (29). The expression and function of Sema4D is still unclear in ALL, and the aim of the present study was to investigate the expression level of Sema4D in pediatric ALL and its potential association with ALL development.

\section{Materials and methods}

Sample collection. Leukemia, including ALL and acute myeloid leukemia (AML), was diagnosed according to standard clinical and laboratory criteria (30). The present study included newly diagnosed patients with pediatric leukemia and healthy pediatric donors who presented no history of leukemia. The samples of the healthy group and the patient group in the experiment were collected from January 2018 to December 2018 in Kunming Children's Hospital (Kunming, China). The age range of the healthy group was 1-12 years old, including 15 males and 13 females; the age range of the patient group was 10 months to 13 years old, including 34 males and 27 females. The details of each patient group are presented in Table SI. Peripheral blood was collected from 18 patients with pediatric leukemia and 6 healthy children, and peripheral blood mononuclear cells (PBMCs) were isolated by density centrifugation at $2,000 \mathrm{x} \mathrm{g}$ for $10 \mathrm{~min}$ at $4^{\circ} \mathrm{C}$ using Ficoll solution, followed by washing with PBS. Plasma was collected from 55 patients with pediatric leukemia and 22 healthy children for ELISA analysis. Of the 18 patients with pediatric leukemia whose PBMCs were isolated, the plasma samples of only 12 patients were included in the ELISA analysis, as the amount of plasma obtained from the remaining 6 patients was insufficient.
Determination of soluble Sema4D in plasma. Plasma was collected and stored at $-80^{\circ} \mathrm{C}$ after total blood was centrifuged at $2,000 \mathrm{x} \mathrm{g}$ for $10 \mathrm{~min}$ at $4^{\circ} \mathrm{C}$. Soluble Sema4D plasma levels were measured using Sema4D ELISA kit (cat. no. MBS705483; MyBioSource, Inc.) according to the manufacturer's instructions. In brief, a microtitration plate coated with anti-Sema4D antibodies was incubated with plasma samples or Sema4D protein standard for $2 \mathrm{~h}$ at $37^{\circ} \mathrm{C}$. It was then incubated with biotin-conjugated anti-Sema4D antibodies for $2 \mathrm{~h}$ at $37^{\circ} \mathrm{C}$. After being washed with the washing solution provided in the kit, it was incubated with HRP-coupled streptavidin for $20 \mathrm{~min}$ at $37^{\circ} \mathrm{C}$. and then incubated with HRP substrate for $15 \mathrm{~min}$ at $37^{\circ} \mathrm{C}$. Following termination of the reaction, the absorbance was measured at $450 \mathrm{~nm}$.

Cell culture and lentiviral infection. Jurkat and BALL-1 cell lines (Shanghai Yihe Applied Biotechnology Co., Ltd. China) were both cultured in RPMI-1640 supplemented with 10\% FBS and $1 \%$ penicillin and streptomycin (all from Gibco; Thermo Fisher Scientific, Inc.) at $37^{\circ} \mathrm{C}$ with $5 \% \mathrm{CO}_{2}$. The cell lines had been confirmed to be mycoplasma free and authenticated by STR profiling. Sema4D cDNA (Sema4D) and short hairpin (sh)RNA were subcloned into the lentiviral vector PWPI-GFP (kindly provided by Dr John Basile, University of Maryland) to obtain lentiviral Sema4D overexpression (Sema4D) and shRNA (S4DshRNA) constructs, and the empty lentiviral vector PWPI-GFP was used as negative control in further analysis. 293T cells (Institute of Medical Biology, Chinese Academy of Medical Sciences and Peking Union Medical College) were cultured in high glucose DMEM (Gibco; Thermo Fisher Scientific, Inc.) with $10 \%$ FBS and $1 \%$ penicillin and streptomycin at $37^{\circ} \mathrm{C}$ with $5 \% \mathrm{CO}_{2}$. Lentiviruses were produced by transfecting $293 \mathrm{~T}$ cells $\left(5 \times 10^{5}\right.$ cells in six-wells plates incubated overnight), with $1.5 \mu \mathrm{g}$ lentiviral plasmid, $0.5 \mu \mathrm{g}$ PVSVG plasmid and $1 \mu \mathrm{g}$ PASPAX plasmid (kindly provided by Dr John Basile, University of Maryland) with Lipofectamine ${ }^{\circledR} 2000$ (Thermo Fisher Scientific, Inc.). Viral supernatants were collected $72 \mathrm{~h}$ after transfection. Jurkat and BALL-1cells were infected with lentiviruses at a MOI of 30 with $4 \mu \mathrm{g} / \mathrm{ml}$ polybrene (Beijing Solarbio Science $\&$ Technology Co., Ltd.) for $72 \mathrm{~h}$ before collection for subsequent analysis.

Western blot analysis. Jurkat and BALL-1 cells were lysed with RIPA buffer (Beijing Solarbio Science \& Technology Co., Ltd.) containing protease inhibitors. Protein concentration was determined using the BCA method, and $50 \mu \mathrm{g}$ protein/sample were separated by $10 \%$ SDS-PAGE and transferred to PVDF membranes, which were blocked at room temperature for 40 min using 5\% BSA solution (Beijing Solarbio Science \& Technology Co., Ltd.). The membranes were incubated at $4^{\circ} \mathrm{C}$ overnight with the following primary antibodies: Mouse anti-Sema4D (1:1,000; cat. no. 610671; BD Biosciences), rabbit anti-ERK (1:2,000; cat. no. 9126S), rabbit anti-phosphorylated (p)-ERK (1:2,000; cat. no. 4376S), rabbit anti-AKT $(1: 2,000$; cat. no. 9272S), rabbit anti-p-AKT (1:2,000; cat. no. 9611S), rabbit anti-PI3K (1:2,000; cat. no. 4257S), rabbit anti-p-PI3K (1:2,000; cat. no. 4228S; all from Cell Signaling Technology, Inc.) and rabbit anti- $\beta$-actin (1:100,000; cat. no. AC026; ABclonal Biotech Co., Ltd.). Following primary antibody 
incubation, the membranes were incubated at room temperature for $1 \mathrm{~h}$ with goat anti-mouse $\lg \mathrm{G}(\mathrm{H}+\mathrm{L})(1: 5,000$; cat. no. 074-1806) and goat anti-rabbit $\lg \mathrm{G}(\mathrm{H}+\mathrm{L})$ antibodies (1:5,000; cat. no. 074-1506; both from KPL). The protein signal was detected using SuperSignal reagent (MilliporeSigma) and quantified using ImageJ software v1.8.0 (National Institutes of Health).

Cell counting kit-8 (CCK-8) assay. Cell viability was analyzed by CCK- 8 assay (Tongren Institute of Chemistry). Jurkat and BALL-1 cells $\left(5 \times 10^{6}\right)$ were lentivirally transduced for $72 \mathrm{~h}$, and $5 \times 10^{4}$ cells $/ \mathrm{ml}$ were seeded in 96-well plates. At 1, 2, 3, 4 and 5 days, cells were incubated with $10 \mu \mathrm{l}$ CCK- 8 solution for $2 \mathrm{~h}$ at $37^{\circ} \mathrm{C}$ with $5 \% \mathrm{CO}_{2}$ and the absorbance at $450 \mathrm{~nm}$ was measured.

Cell migration and invasion assay. Cell migratory capacity was detected by Transwell assay. The lentivirally transduced Jurkat and BALL-1 cells were cultured to logarithmic growth phase, adjusted to $1 \times 10^{4}$ cells/ml with RPMI-1640 basal medium containing $0.1 \%$ BSA (Beijing Solarbio Science \& Technology Co., Ltd.), and placed on top of each compartment of $0.8 \mu \mathrm{m}, 24$-well Transwell chamber (Corning, New York, USA), and RPMI-1640 medium containing 10\% FBS was added to lower chamber of the plates. After the cells were cultured for $24 \mathrm{~h}$ at $37^{\circ} \mathrm{C}$, the cell number in the lower chamber was counted using a hemocytometer. Cell invasive capacity was also determined by Transwell cell assay. A total of $100 \mu 1300 \mu \mathrm{g} / \mathrm{ml}$ Matrigel (BD Biosciences) were thawed at $4^{\circ} \mathrm{C}$ overnight before being placed into the upper chamber and incubated at $37^{\circ} \mathrm{C}$ for $1 \mathrm{~h}$. The lentivirally transduced Jurkat and BALL-1 cells were cultured to logarithmic growth phase, adjusted to $1 \times 10^{4}$ cells/ml with RPMI-1640 basal medium containing $0.1 \%$ BSA and placed on top of each compartment. RPMI-1640 medium with $10 \%$ FBS was then added to the lower chambers. After the cells were cultured for $24 \mathrm{~h}$ at $37^{\circ} \mathrm{C}$, the cell number in the lower chamber was counted using a hemocytometer.

Apoptosis analysis. Apoptosis was detected using PE Annexin V Apoptosis Detection Kit I (BD Biosciences). After lentiviral transduction for $72 \mathrm{~h}$, Jurkat and BALL-1 cells were washed with pre-chilled PBS and were adjusted to $1 \times 10^{6}$ cells $/ \mathrm{ml}$ with $1 \mathrm{x}$ Binding Buffer. The cells were incubated at room temperature with $5 \mu \mathrm{l} \mathrm{PE}$ Annexin $\mathrm{V}$ and $5 \mu \mathrm{l}$ 7-AAD for 15 min before being analyzed by Attune NxT flow cytometry (Thermo Fisher Scientific, Inc.), and the data were analyzed using Treestar FlowJo version 10 software (Becton, Dickinson and Company).

Cell cycle analysis. After lentiviral transduction for $72 \mathrm{~h}$, Jurkat and BALL-1 cells were washed with pre-chilled PBS, before being suspended in pre-chilled PBS and fixed with ice-cold absolute ethanol at $-20^{\circ} \mathrm{C}$ overnight. After being washed with ice-cold PBS, the cells were incubated with $50 \mu \mathrm{g} / \mathrm{ml}$ RNase A and $65 \mu \mathrm{g} / \mathrm{ml}$ propidium iodide (BD Biosciences) at $4^{\circ} \mathrm{C}$ for 30 min before analysis by Attune NxT flow cytometry (Thermo Fisher Scientific, Inc.), and the data were analyzed using Treestar FlowJo version 10 software (Becton, Dickinson and Company).
Overall survival analysis. The analysis was performed on the GEPIA website (http://gepia.cancer-pku.cn) using the median expression of Sema4D as cut-off to differentiate low and high Sema4D expression groups and 95\% confidence interval.

Statistical analysis. The statistical analysis was performed by SPSS software version 21.0 (IBM Corp.). Experimental values are presented as the mean \pm SD. Statistical analysis in Fig. 1 and Figs. 3-6 was performed using one-way ANOVA followed by Bonferroni's post hoc test. Statistical analysis in Fig. 2 was performed using two-way ANOVA followed by Bonferroni's post hoc test. Statistical analysis in Fig. 7B was performed using unpaired two-tailed Student's t-test. The correlation between the level of p-PI3K, p-ERK or p-AKT and Sema4D in Fig. 7C was evaluated using Pearson's correlation analysis (two-sided). $\mathrm{P}<0.05$ was considered to indicate a statistically significant difference.

\section{Results}

Sema4D is highly expressed in pediatric leukemia. To investigate the expression level of Sema4D in pediatric leukemia cells, the mononuclear cell lysates of 18 patients with pediatric leukemia and 6 healthy children were subjected to western blot analysis. The clinical details of the 18 patients with pediatric leukemia are presented in Table SII. The results revealed that Sema4D was highly expressed in patients with pediatric leukemia compared with healthy participants (Fig. 1A). As the majority of patients were B cell-ALL patients, it was subsequently determined whether there were any differences in Sema4D expression level between B cell-ALL and other types of leukemia. Therefore, patients were divided into either $B$ cell-ALL (B-ALL) or non-B cell-ALL groups (Non-B-ALL). The analysis indicated that Sema4D expression level in both groups was significantly higher compared with that in the control group $(\mathrm{P}<0.01)$, and there was no difference in Sema4D expression level between the B-ALL and Non-B-ALL groups (Fig. 1B).

As Sema4D can be cleaved to functional soluble Sema4D, which is secreted from cells (23), the level of soluble Sema4D in the plasma of patients with leukemia was examined. The plasma of 55 pediatric patients with leukemia and 22 healthy children was collected and analyzed by ELISA. The clinical details of the 55 pediatric patients with leukemia are listed in Table SII. The results revealed that the level of soluble Sema4D in the B-ALL and Non-B-ALL groups was higher compared with that in healthy children $(\mathrm{P}<0.01$ for $\mathrm{B}-\mathrm{ALL} ; \mathrm{P}<0.05$ for Non-B-ALL), and there was no difference in Sema4D level between the B-ALL and Non-B-ALL groups (Fig. 1C).

Taken together, the results indicated that Sema4D was highly expressed in patients with pediatric leukemia, and soluble Sema4D was released into the circulation in these patients. However, there was no difference in Sema4D levels between B-ALL and other types of leukemia in both leukemia cells and plasma.

Sema4D promotes proliferation. As the results indicated that Sema4D was highly expressed in pediatric leukemia, the potential role of Sema4D in leukemia development was subsequently investigated. To examine the function of 
A
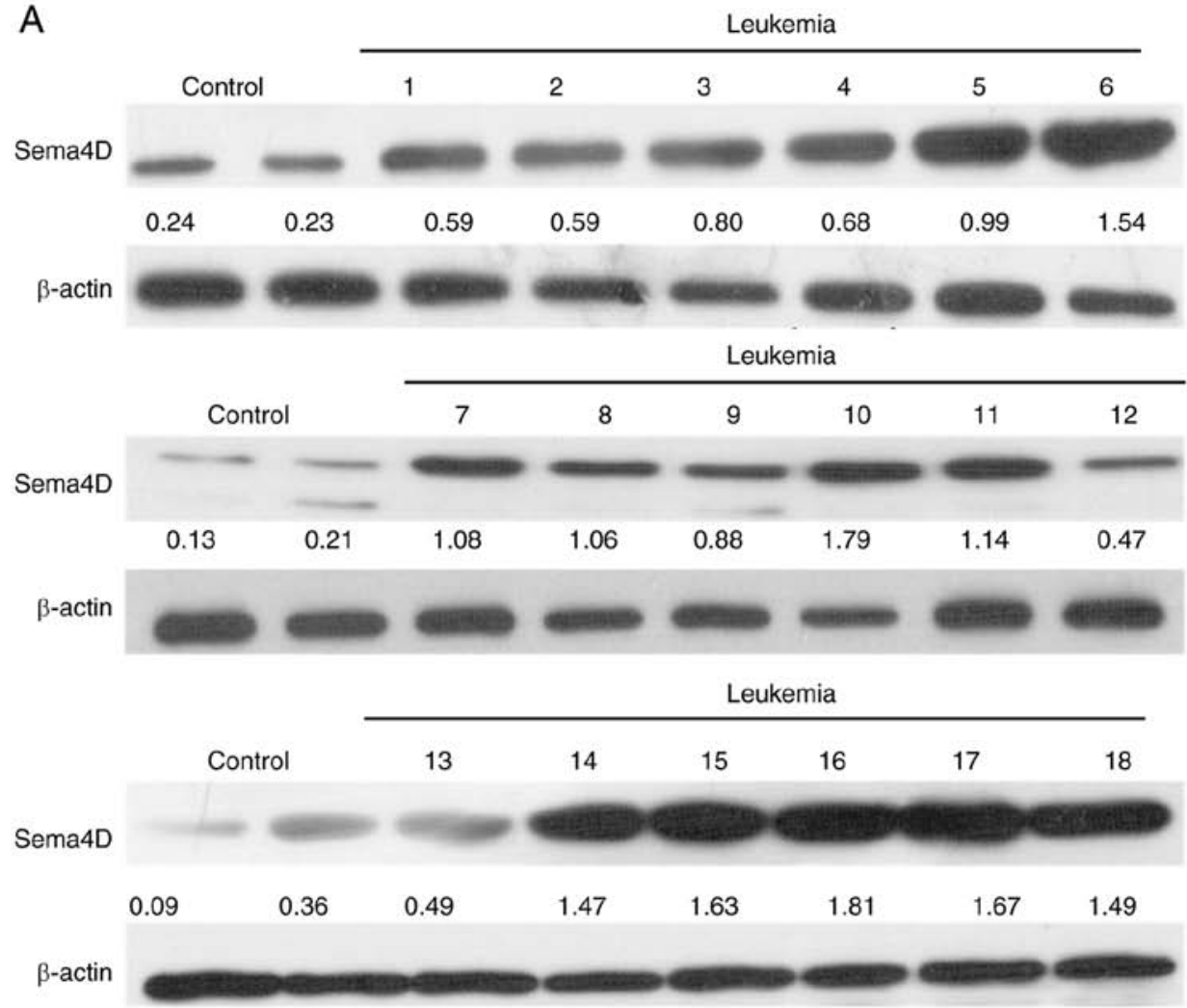

B

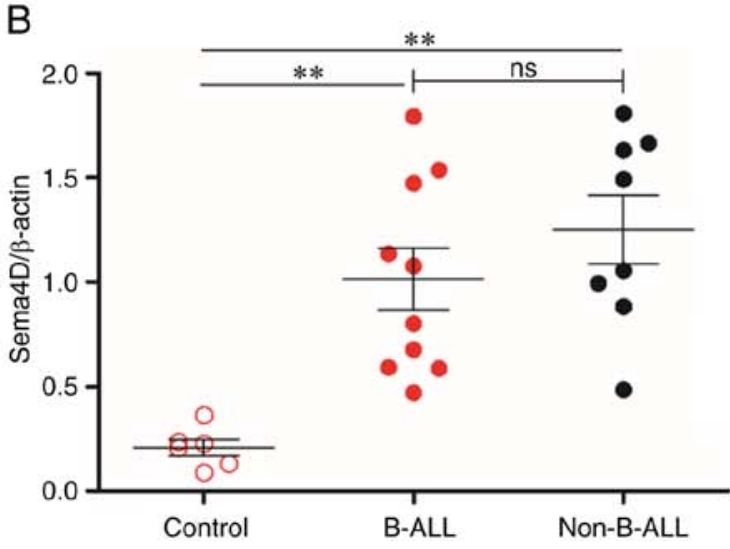

C

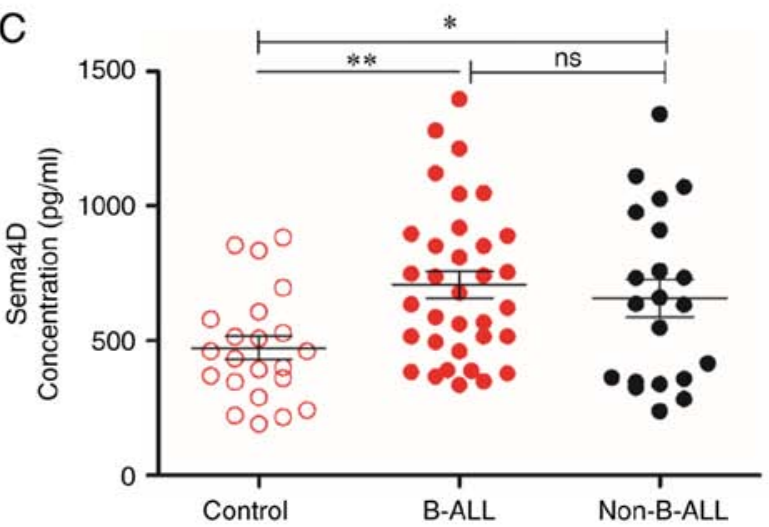

Figure 1. Sema4D is highly expressed in pediatric leukemia. (A) Sema4D protein expression in peripheral blood mononuclear cells from 18 patients with pediatric leukemia and 6 healthy control children. The protein level of each blot was quantified relatively to the internal control $\beta$-actin. (B) Quantification of Sema4D protein expression level in B-ALL $(n=10)$ and Non-B-ALL $(n=8)$. (C) Soluble Sema4D level in the peripheral blood. Data are presented as the mean \pm SD. ${ }^{*} \mathrm{P}<0.05 ;{ }^{* *} \mathrm{P}<0.01$. ns, not significant; B-ALL, B cell acute lymphocytic leukemia; Sema4D, semaphorin 4D.

Sema4D, the Jurkat cell line, which originates from $\mathrm{T}$ cell ALL, and the BALL-1 cell line, which originates from B cell ALL, were selected for the study. Sema4D overexpressing and S4DshRNA lentiviruses were transduced into Jurkat and BALL-1 cells. Sema4D expression level in Jurkat and BALL-1 cells was detected by western blotting after transduction for $72 \mathrm{~h}$. The results indicated that Sema4D expression in both cell lines was reduced after transduction with S4DshRNA, and increased after transduction with the Sema4D overexpressing lentivirus compared with uninfected cells or cells infected with the empty vector (GFP) (Fig. 2A). The viability of Jurkat and BALL-1 cells was assessed by CCK- 8 assay after transduction for $72 \mathrm{~h}$. The results demonstrated that the viability of both Jurkat and BALL-1 cells was significantly decreased after transduction with S4DshRNA $(\mathrm{P}<0.001$ in Jurkat and $\mathrm{P}<0.01$ in BALL-1), while it was significantly increased after transduction with Sema4D overexpression construct (both $\mathrm{P}<0.001$ ) (Fig. 2B). The results suggested that Sema4D promoted the proliferation of Jurkat and BALL-1 cells.

Sema4D modulates the $G_{0} / G_{1}$ phase of the cell cycle. Subsequently, the effect of Sema4D on cell cycle was examined in Jurkat and BALL-1 cells. The results revealed that the percentage of cells in the $\mathrm{G}_{0} / \mathrm{G}_{1}$ phase significantly increased after transduction with S4DshRNA ( $\mathrm{P}<0.01)$, and significantly decreased after transduction with the Sema4D overexpression construct $(\mathrm{P}<0.05)$ in BALL-1 cells (Fig. $3 \mathrm{~A}$ and $\mathrm{B})$. The cell percentage in the $G_{0} / G_{1}$ phase also significantly decreased 


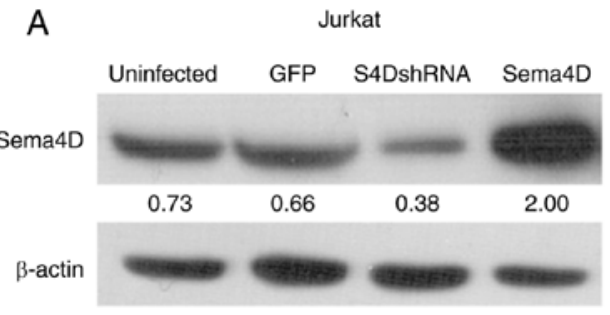

B

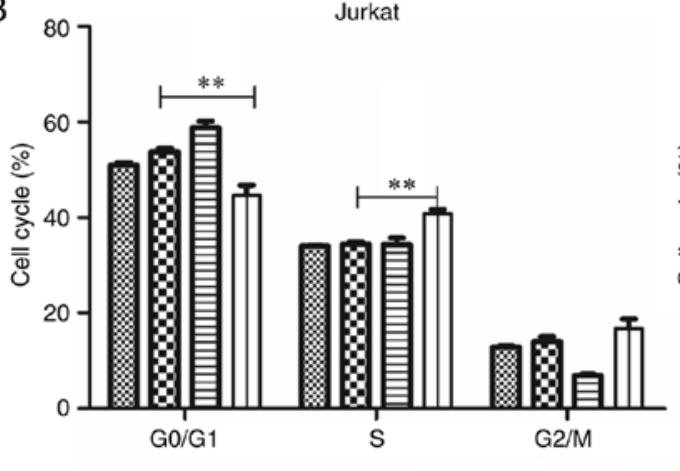

B
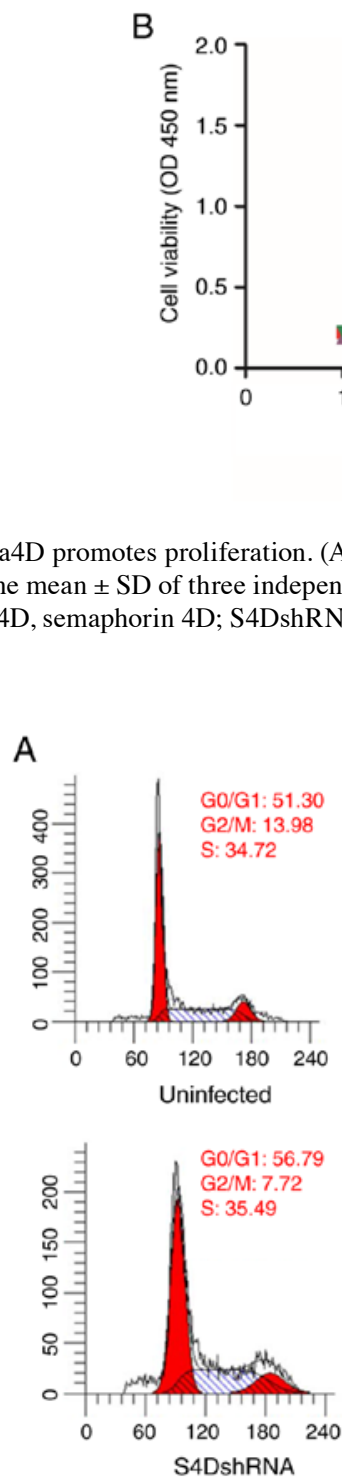

Jurkat
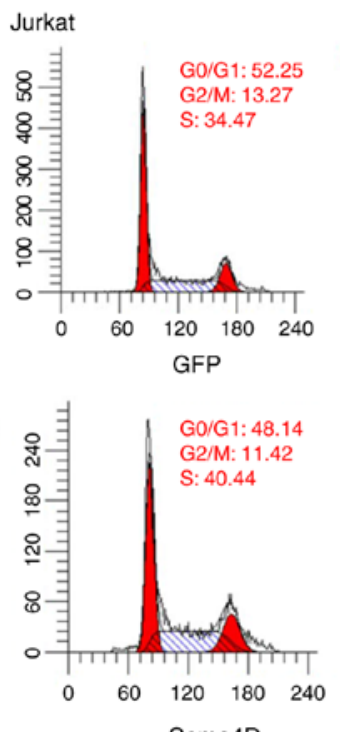

Sema4D

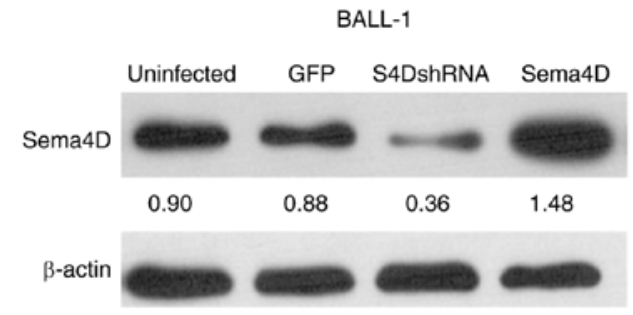

BALL-1

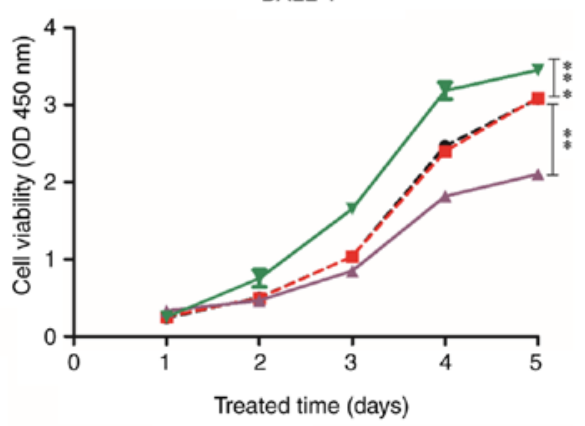

$\rightarrow$ Uninfected $\rightarrow$ GFP $₫$ S4DshRNA $\rightarrow$ Sema4D

Figure 2. Sema4D promotes proliferation. (A) Sema4D protein expression in Jurkat and BALL-1 cells. (B) Viability of Jurkat and BALL-1 cells. Viability is presented as the mean \pm SD of three independent experiments. ${ }^{* *} \mathrm{P}<0.01$ and ${ }^{* * *} \mathrm{P}<0.001$ vs. GFP and S4DshRNA or GFP and Sema4D. GFP, green fluorescent protein; Sema4D, semaphorin 4D; S4DshRNA, Sema4D short hairpin RNA; OD, optical density.

Uninfected $\infty$ GFP
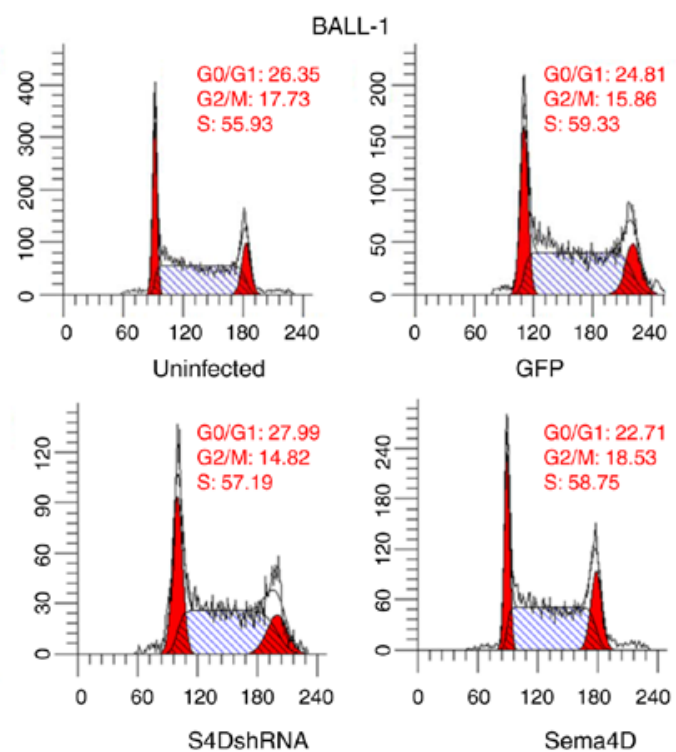

BALL-1

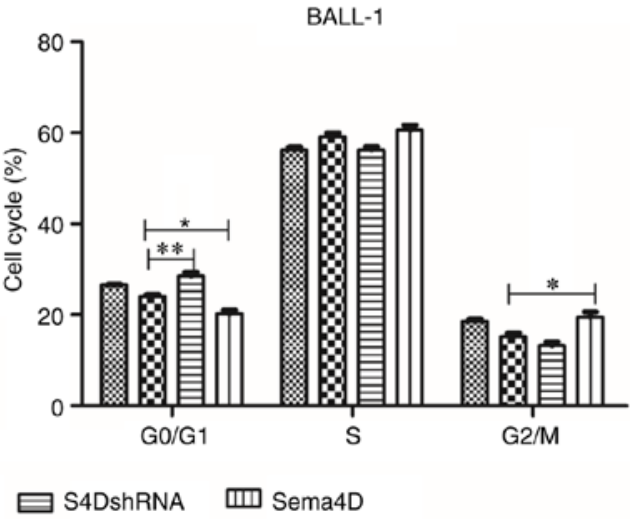

Figure 3. Sema4D modulates the cell cycle. (A) Representative flow cytometry plots of the cell cycle in Jurkat and BALL-1 cells. (B) Bar graphs of cell cycle distribution. Data are presented as the mean \pm SD of three independent experiments. ${ }^{*} \mathrm{P}<0.05 ;{ }^{* *} \mathrm{P}<0.01$. GFP, green fluorescent protein; Sema4D, semaphorin $4 \mathrm{D}$; S4DshRNA, Sema4D short hairpin RNA. 
A

Jurkat

BALL-1

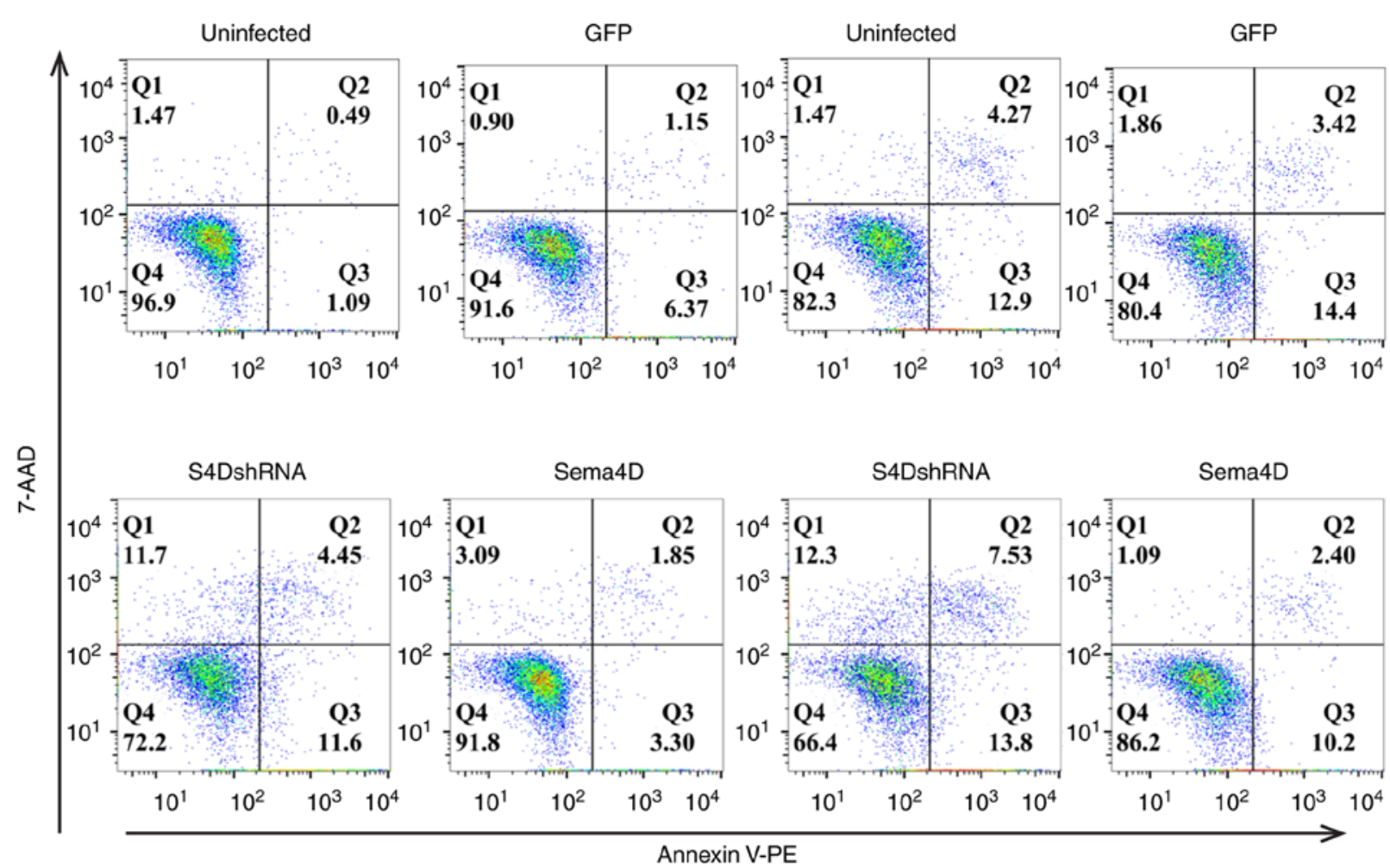

B
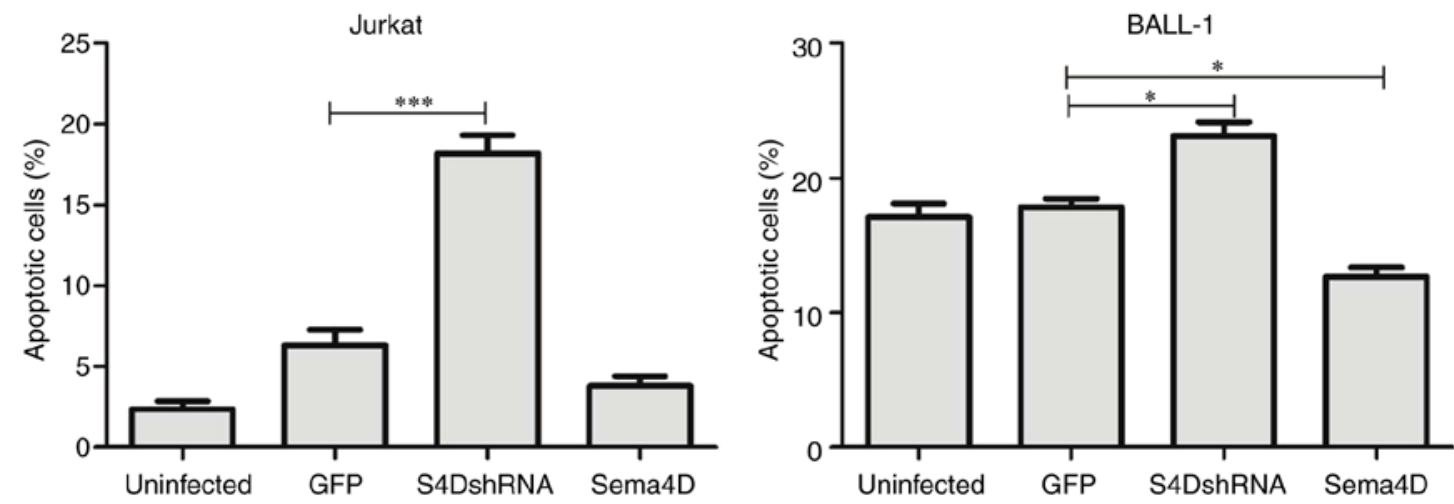

Figure 4. Sema4D inhibits apoptosis. (A) Representative flow cytometry plots of the apoptosis analysis. (B) Bar graphs of cell counts. Data are presented as the mean $\pm \mathrm{SD}$ of three independent experiments. ${ }^{*} \mathrm{P}<0.05 ;{ }^{* * *} \mathrm{P}<0.001$. GFP, green fluorescent protein; Sema4D, semaphorin $4 \mathrm{D} ;$ S4DshRNA, Sema4D short hairpin RNA.

after transduction with the Sema4D overexpression construct in Jurkat cells $(\mathrm{P}<0.01)$, but was not altered after transduction with S4DshRNA, as the percentage of Jurkat cells in the $\mathrm{G}_{0} / \mathrm{G}_{1}$ phase was already high (Fig. 3A and B). As a consequence of the decreased abundance of cells in the $\mathrm{G}_{0} / \mathrm{G}_{1}$ phase caused by Sema4D overexpression, the percentage of Jurkat cells in the $S$ phase or BALL-1 cells in the $\mathrm{G}_{2} / \mathrm{M}$ phase increased significantly compared with the control $(\mathrm{P}<0.01$ for Jurkat; $\mathrm{P}<0.05$ for BALL-1 cells). The results suggested that downregulation of Sema4D induced cell cycle arrest at the $\mathrm{G}_{0} / \mathrm{G}_{1}$ phase, and Sema4D modulated the $\mathrm{G}_{0} / \mathrm{G}_{1}$ phase of the cell cycle.

Sema4D inhibits apoptosis. The effect of Sema4D on apoptosis was also investigated. In Jurkat cells, the number of apoptotic cells was significantly higher in the S4DshRNA group ( $\mathrm{P}<0.001$; Fig. 4A and B). Similarly, in BALL-1 cells, the number of apoptotic cells was significantly higher in the S4DshRNA group $(\mathrm{P}<0.05)$ and was significantly lower in Sema4D overexpression group compared with the GFP control group $(\mathrm{P}<0.05)$ (Fig. 4A and B). These results indicated that Sema4D protected leukemia cells from apoptosis.

Sema $4 D$ promotes the migratory and invasive abilities of leukemia cells. To evaluate the effects of Sema4D on cell invasion and migration, Jurkat and BALL-1 cells were transduced with Sema4D overexpression construct or S4DshRNA, and their migratory and invasive abilities were examined by Transwell assay. In Jurkat cells, no difference was observed in the invasive ability among the GFP control, S4DshRNA and Sema4D overexpression groups (Fig. 5A), while the migratory ability increased significantly in the Sema4D overexpression group compared with the GFP control $(\mathrm{P}<0.05 ;$ Fig. $5 \mathrm{C})$. In 

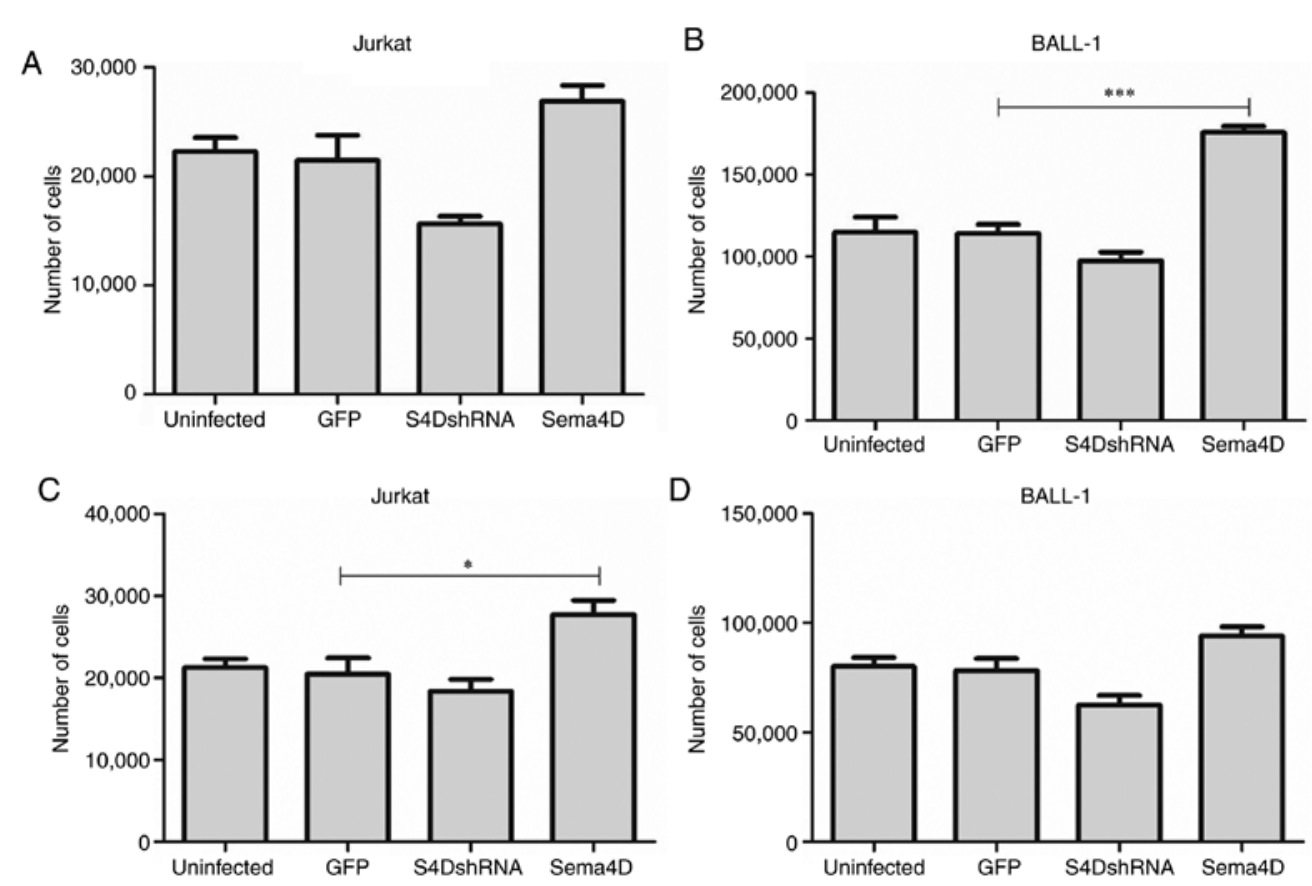

Figure 5. Sema4D promotes cell invasion and migration. (A) Jurkat cells invasive ability. (B) BALL-1 cells invasive ability. (C) Jurkat cells migratory ability. (D) BALL-1 cells migratory ability. Data are presented as the mean \pm SD of three independent experiments. ${ }^{*} \mathrm{P}<0.05 ;{ }^{* * *} \mathrm{P}<0.001$. GFP, green fluorescent protein; Sema4D, semaphorin 4D; S4DshRNA, Sema4D short hairpin RNA.

A

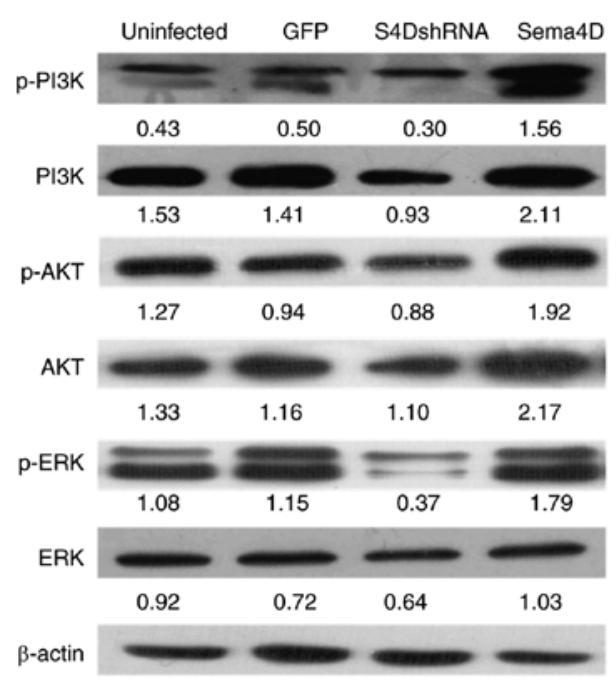

B

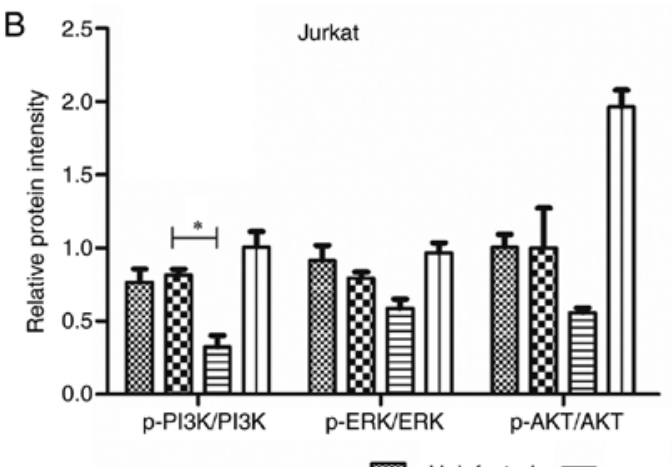

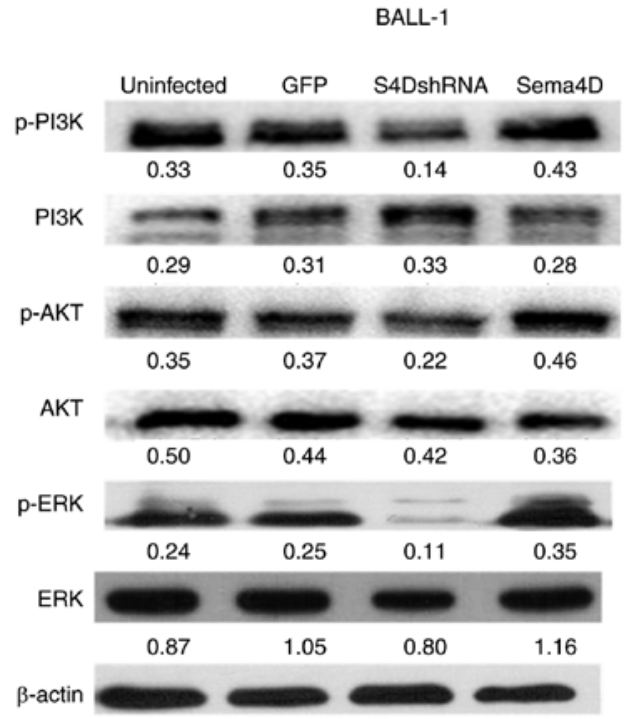

BALL-1

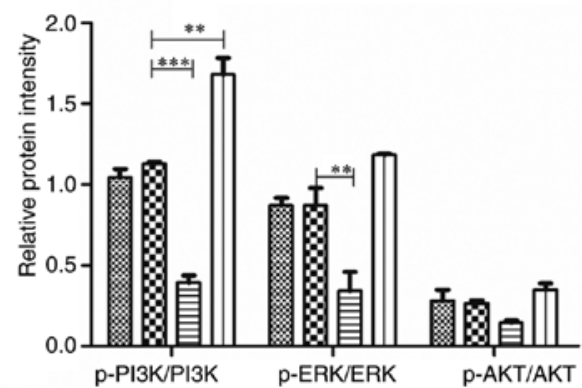

Figure 6. Sema4D induces phosphorylation of PI3K, ERK and AKT. (A) Protein expression and phosphorylation of PI3K, ERK and AKT in Jurkat and BALL-1 cells with $\beta$-actin as internal control. (B) Ratios of p-PI3K/PI3K, p-AKT/AKT and p-ERK/ERK in Jurkat and BALL-1 cells. Data are presented as the mean \pm SD of three independent experiments. ${ }^{*} \mathrm{P}<0.05 ;{ }^{* *} \mathrm{P}<0.01 ;{ }^{* * *} \mathrm{P}<0.001$. GFP, green fluorescent protein; Sema4D, semaphorin 4D; S4DshRNA, Sema4D short hairpin RNA; p, phosphorylated. 
A
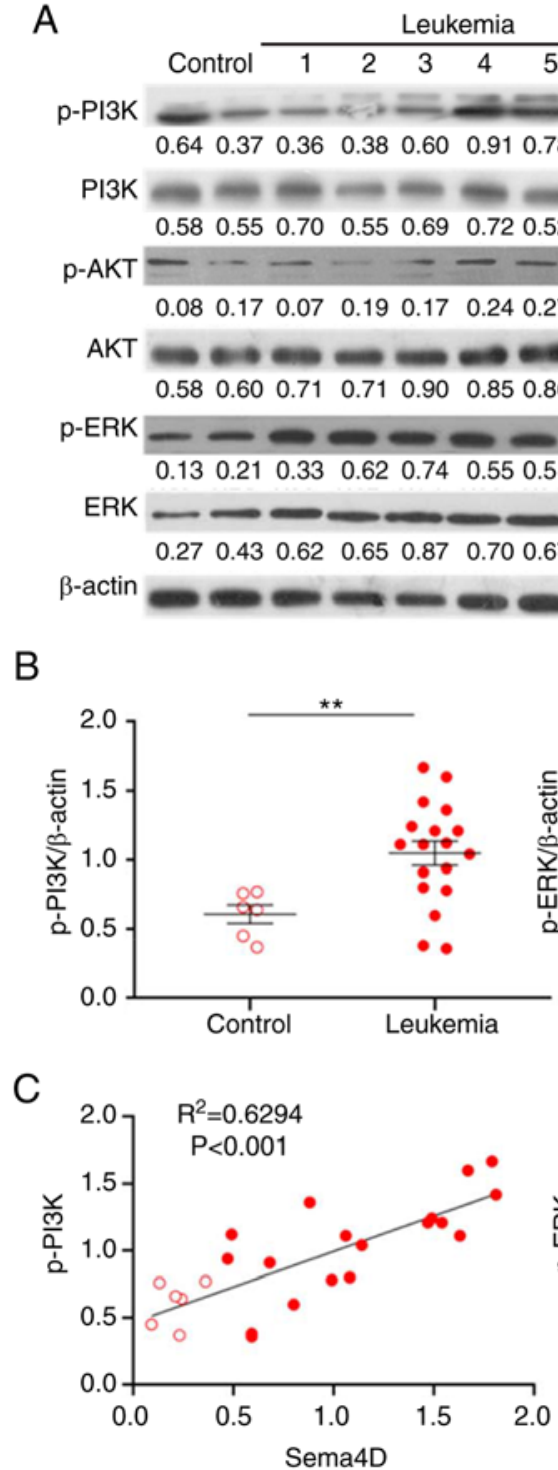
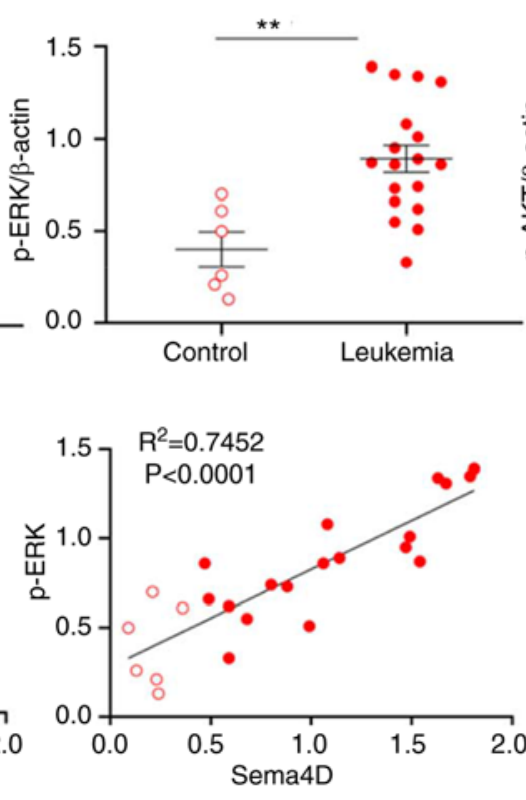

Leukemia

Control $7 \quad 8 \quad 9 \quad 10 \quad 11 \quad 12$

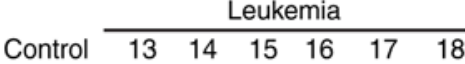

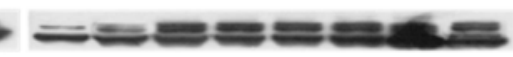

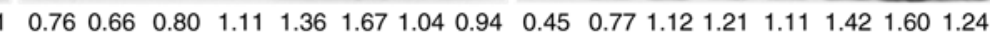

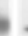

$=\frac{1}{0.31}-\frac{}{0.63}-\frac{1}{0.45}$

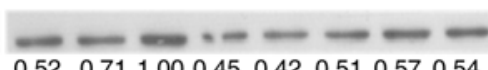

$\begin{array}{lllllllllllll}0.52 & 0.71 & 1.00 & 0.45 & 0.42 & 0.51 & 0.57 & 0.54\end{array}$

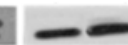

$\begin{array}{llllllll}0.56 & 0.88 & 1.22 & 1.59 & 1.44 & 1.84 & 1.29 & 1.22\end{array}$

$0.44 \quad 0.901 .271 .251 .391 .601 .560 .94$
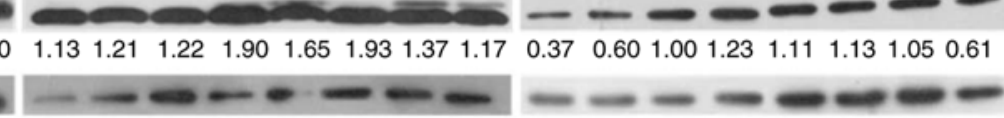

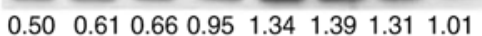

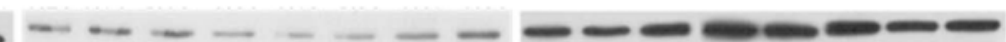

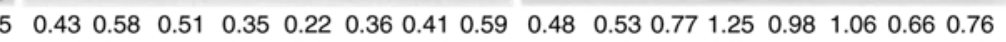
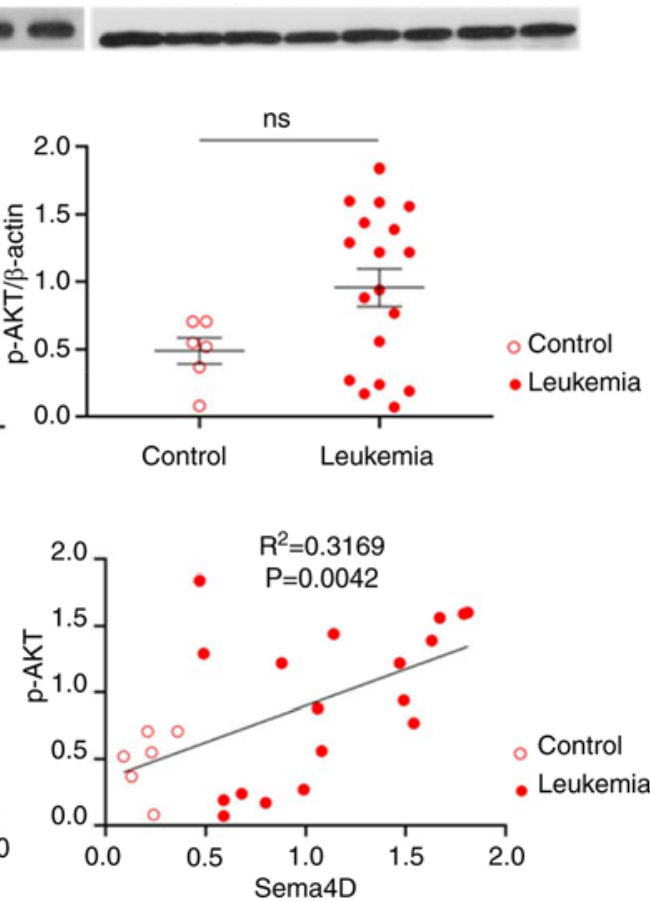

Figure 7. Phosphorylation of PI3K, ERK and AKT is correlated with the expression of Sema4D in patients with pediatric leukemia. (A) Protein expression and phosphorylation of PI3K, ERK and AKT proteins in peripheral blood mononuclear cells from 18 patients with pediatric leukemia and 6 healthy control children. $\beta$-actin was used as an internal control. (B) Quantification of the total p-PI3K, p-ERK and p-AKT levels in patients with leukemia and healthy controls. (C) Correlation between Sema4D expression and p-PI3K, p-ERK and p-AKT levels in leukemia and healthy groups. Data are presented as the mean \pm SD. ${ }^{* *} \mathrm{P}<0.01$. ns, not significant; $\mathrm{p}$, phosphorylated; Sema4D, semaphorin 4D.

BALL-1 cells, compared with the GFP group, the invasive ability increased significantly in the Sema4D overexpression group $(\mathrm{P}<0.001$; Fig. 5B), while no difference was observed in the migratory ability among the GFP control, S4DshRNA and Sema4D overexpression groups (Fig. 5D). As Jurkat and BALL-1 cell lines originate from T-ALL and B-ALL, respectively, their different migratory and invasive capabilities may be due to their original characteristics. Overall, these data suggested that Sema4D moderately promoted the invasive and migratory ability of ALL cells.

Sema4D activates the PI3K, ERK and AKT proteins. As the results had indicated that Sema4D promoted proliferation and inhibited apoptosis, it was subsequently investigated how these effects were mediated.PI3K, AKT and ERK proteins, which are widely expressed in a variety of tumor tissues (31-35), promote cancer development by mediating activation of downstream effectors (31,36-39). The role of Sema4D in activating PI3K, AKT and ERK was examined in Jurkat and BALL-1 cells. In Sema4D-overexpressing BALL-1 cells, the phosphorylation level of PI3K was significantly increased compared with the GFP control cells $(\mathrm{P}<0.01$; Fig. 6). However, potentially owing to the high endogenous expression of Sema4D in both Jurkat and BALL-1 cells, Sema4D overexpression did not consistently elevate the phosphorylation level of PI3K, ERK and AKT.

In Sema4D knocked-down BALL-1 cells, the phosphorylation level of PI3K and ERK significantly decreased compared with the GFP control cells $(\mathrm{P}<0.001$ for PI3K and $\mathrm{P}<0.01$ for ERK; Fig. 6A and B). In Sema4D knocked-down Jurkat cells, the phosphorylation level of PI3K was also significantly decreased $(\mathrm{P}<0.05$; Fig. $6 \mathrm{~A}$ and $\mathrm{B})$. The alteration in the AKT phosphorylation level was not statistically significant in both Jurkat and BALL-1 cell lines. The Sema4D knockdown results 


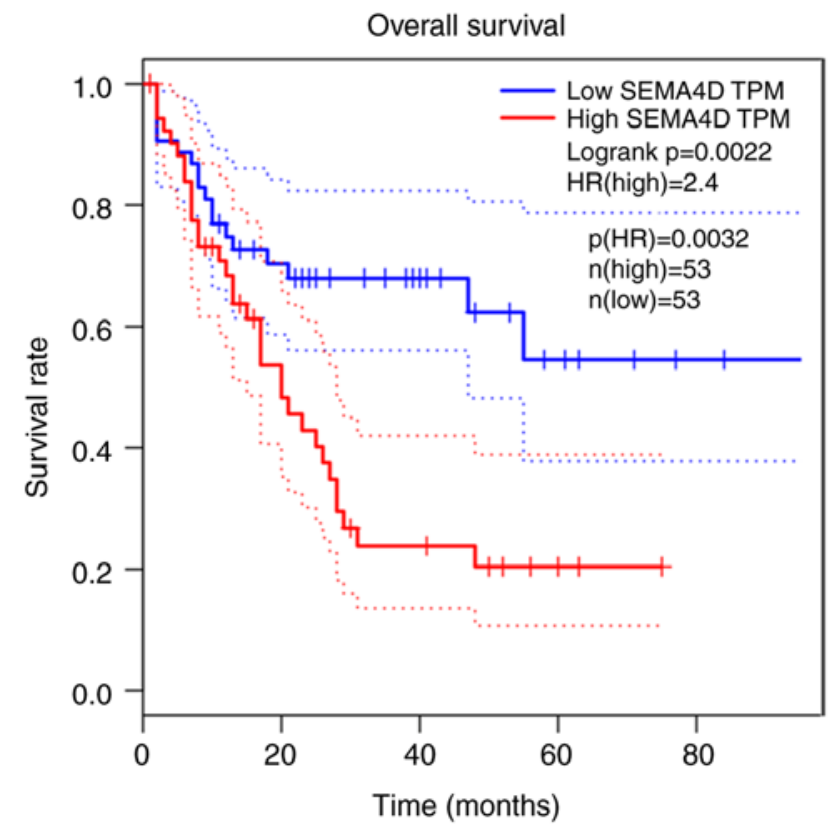

Figure 8. High Sema4D expression is associated with shorter overall survival in AML. Analysis of the association between Sema4D RNA expression level and overall survival of AML patients using GEPIA website. The AML dataset was divided into low and high expression groups according to the median value of Sema4D expression. Sema4D, semaphorin 4D; AML, acute myeloid leukemia; HR, hazard ratio.

indicated that Sema4D mediated the activation of PI3K and ERK in ALL cells.

Phosphorylation of PI3K, ERK and AKT is correlated with the expression of Sema4D in pediatric leukemia. In order to ascertain the clinical relevance of PI3K, ERK and AKT pathways, the expression and phosphorylation levels of PI3K, ERK and AKT were analyzed by western blotting in 18 pediatric leukemia samples, in which the expression of Sema4D had been examined (Fig. 1A and B). Since no difference was observed in the expression level of Sema4D between the B-ALL and Non-B-ALL groups, both groups were analyzed together regarding the expression and phosphorylation of PI3K, ERK and AKT. There was no significant difference in the expression level of PI3K, ERK and AKT between patients with leukemia and healthy control subjects (data not shown). The total phosphorylation level of PI3K and ERK in the leukemia group was significantly higher compared with the healthy control group $(\mathrm{P}<0.01)$, and the total phosphorylation level of AKT in the leukemia group was higher compared with the healthy control group (all normalized to $\beta$-actin), but with no statistical significance (Fig. 7A and B). The relative phosphorylation level normalized to total PI3K, ERK and AKT was not significantly different between the groups (data not shown). Therefore, the results indicated that the total phosphorylation level of PI3K, ERK and AKT was enhanced in pediatric leukemia. The correlation of Sema4D expression with the phosphorylation level of PI3K, ERK and AKT was further analyzed, and the results indicated that Sema4D expression was significantly correlated with $\mathrm{p}-\mathrm{PI} 3 \mathrm{~K}$ and $\mathrm{p}$-ERK $(\mathrm{P}<0.001$ for $\mathrm{p}-\mathrm{PI} 3 \mathrm{~K} ; \mathrm{P}<0.0001$ for $\mathrm{p}$-ERK $)$ and moderately correlated with $\mathrm{p}-\mathrm{AKT}(\mathrm{P}=0.0042)$, and the expression level of Sema4D and the phosphorylation level of PI3K, ERK and AKT were higher in patients with leukemia compared with healthy subjects (Fig. 7C). The expression of Sema4D was not correlated with the expression of PI3K, ERK and AKT proteins (data not shown). The results depicted in Figs. 6 and 7 suggested that Sema4D activated the PI3K, ERK and AKT pathways in leukemia cells.

Sema4D overexpression is correlated with poor prognosis in AML. As there were no ALL data in the GEPIA website, overall survival was only analyzed in patients with AML, and it was revealed that high expression of Sema4D was associated with shorter overall survival in patients with AML (Fig. 8). Therefore, Sema4D may be a poor prognostic biomarker in leukemia.

\section{Discussion}

Sema4D is highly expressed in several tumor tissues, including breast, lung, colorectal, prostate, oral and pancreatic cancer, head and neck squamous cell carcinoma and soft tissue sarcoma $(10,12,13,16,17)$. Although Sema4D is expressed in B-CLL (40), its expression in other leukemia types has not been reported. Therefore, the expression of Sema4D in pediatric leukemia was examined in the present study. The results demonstrated that there was high expression of Sema4D in PBMCs and a high level of soluble Sema4D in the plasma of patients with pediatric leukemia, with no difference between B-ALL and Non-B-ALL groups. As Non-B-ALL mainly included AML and T cell-ALL, the data suggested that the expression of Sema4D was upregulated in B-ALL and other types of leukemia as well. Therefore, Sema4D may serve an important role in the development of leukemia.

To understand the role of Sema4D in the development of leukemia, its effects on proliferation, apoptosis, cell cycle, invasion and migration were examined in the present study. The results demonstrated that in BALL-1 cells, Sema4D knockdown induced cell cycle arrest in the $G_{0} / G_{1}$ phase, increased apoptosis and inhibited proliferation; on the contrary, overexpression of Sema4D promoted cell division and proliferation and inhibited apoptosis. In Jurkat cells, Sema4D knockdown inhibited proliferation and promoted apoptosis, while Sema4D overexpression resulted in a decreased abundance of cells in the $G_{0} / G_{1}$ phase and promoted proliferation. Taken together, these data suggested that Sema4D promoted proliferation and inhibited apoptosis in leukemia cells. Sema4D overexpression promoted the migratory ability of Jurkat cells and the invasive ability of BALL-1 cells. Sema4D enhanced the invasive and migratory abilities of leukemia cells, although the effect was dependent on the cell origin. These results on the effect of Sema4D on invasion and migration are consistent with a previous study in breast cancer (20).

Sema4D has been indicated to phosphorylate tyrosine kinase receptors [protein-tyrosine kinase 2-beta (Pyk2) or Src] and ERK1/2, and phosphorylated Pyk2 and Src further activate the PI3K/AKT signaling pathway and mediate cell invasion and migration (41). AKT is widely expressed in different types of tumors, such as colorectal, pancreatic, gastric and non-small cell lung cancer cell $(31,32,34,35)$. It has been indicated to associate cancer-promoting molecules and 
downstream signaling molecules in tumor development (42). It has also been demonstrated to promote cell proliferation and inhibit apoptosis (31), and promote metastasis by regulating $\mathrm{Bcl} 2$ and focal adhesion kinase expression (43-45). The results of the present study revealed that knockdown of Sema4D inhibited the phosphorylation PI3K and AKT in both Jurkat and BALL-1 cell lines, suggesting that Sema4D activated the PI3K/AKT signaling pathway, which was also supported by the fact that the phosphorylation of PI3K and AKT was correlated with Sema4D expression in pediatric leukemia samples.

ERK, which is a downstream protein of a variety of growth factors (37-39), has been indicated to be activated in oral, colorectal and gastric cancer (46-49). It transfers extracellular signals to the nucleus to regulate cell proliferation, differentiation and survival. The results of the current study revealed that the phosphorylation level of ERK was significantly decreased in Sema4D knocked-down BALL-1 cells. The phosphorylation level of ERK was also increased in patients with pediatric leukemia and was correlated with the expression level of Sema4D. This indicated that Sema4D activated ERK signaling in leukemia cells.

As the activation of PI3K, AKT and ERK is important in regulating cell proliferation, invasion, migration and apoptosis $(31,42-45)$, we speculate that Sema4D promoted leukemia development via activating the PI3K/AKT and ERK pathways.

Soluble Sema4D, which is released by proteolytic cleavage of the extracellular domain of transmembrane Sema4D, has been indicated to be involved in infectious and inflammatory diseases (2) and heart failure (50). The finding of high levels of soluble Sema4D in the plasma of patients with pediatric leukemia is consistent with results in human head and neck cancer $(25,51)$, suggesting that Sema4D may be a potential biomarker for cancer diagnosis. Soluble Sema4D has also been reported to participate in cancer development by inducing metastasis (25), inhibiting differentiation (52) and suppressing the immune response (53). However, the role of soluble Sema4D in leukemia remains unknown, and further studies are required.

In conclusion, the results of the present study demonstrated that Sema4D was upregulated in the PBMCs of patients with pediatric leukemia and soluble Sema4D was similarly increased in the plasma of these patients. Sema4D was revealed to modulate the cell cycle, promote cell proliferation and invasion and inhibit apoptosis in ALL cells. It was indicated to serve an important role in leukemia development via regulating the PI3K/AKT and ERK signaling pathways. Sema4D may serve as a novel target for leukemia diagnosis and treatment.

\section{Acknowledgements}

Not applicable.

\section{Funding}

The present study was supported by the National Natural Science Foundation of China (grant nos. 81960033 to HJ, 31970868 to QS and 81460028 to MY), the Association Foundation Program of Yunnan Science and Technology Department and Kunming Medical University (grant no. 2019FE001-103 to HJ), the Foundation of the CAMS Initiative for Innovative Medicine (CAMS-I2M) (grant no. 2017-I2M-2-006 to QS), the Foundation of Yunnan Medical Science and Technology (grant no. 2016NS124 to HJ), Yunnan Health Training Project of High Level Talents (grant no. D-2017053 to HJ), Top Young Experts Training Project for the Academy and Technology in Kunming and Yunnan Province to HJ (grant no. 202005AC160066), Postdoctoral Training Program of Yunnan Province (grant no. Ynbh19035 to $\mathrm{HJ}$ ) and Natural Science Foundation of Yunnan Province (grant no. 2019-1-C-25318000002240 to HJ).

\section{Availability of data and materials}

All data generated or analyzed during this study are included in this published article.

\section{Authors' contributions}

HJ and JT confirm the authenticity of the raw data. HJ designed and performed the experiments. JT performed the experiments and prepared the manuscript. SS, LX, LK, TH, WN, $\mathrm{BZ}$ and $\mathrm{CZ}$ obtained and arranged the clinical specimens and performed clinical analysis. LQ performed clinical analysis and western blot of clinical samples. MY, QS and ZZ proposed the idea, designed and supervised the project, analyzed and interpreted the data and revised the manuscript. All authors read and approved the final manuscript.

\section{Ethics approval and consent to participate}

The present study was approved by the Ethics Committee of the Affiliated Children's Hospital of Kunming Medical University (Kunming, China), and written informed consent was obtained from each donor's guardian.

\section{Patient consent for publication}

Not applicable.

\section{Competing interests}

The authors declare that they have no competing interests.

\section{References}

1. Hall KT, Boumsell L, Schultze JL, Boussiotis VA, Dorfman DM, Cardoso AA, Bensussan A, Nadler LM and Freeman GJ: Human CD100, a novel leukocyte semaphorin that promotes B-cell aggregation and differentiation. Proc Natl Acad Sci USA 93: 11780-11785, 1996

2. Maleki KT, Cornillet $M$ and Björkström NK: Soluble SEMA4D/CD100: A novel immunoregulator in infectious and inflammatory diseases. Clin Immunol 163: 52-59, 2016.

3. Mou P, Zeng Z, Li Q, Liu X, Xin X, Wannemacher KM, Ruan C, Li R, Brass LF and Zhu L: Identification of a calmodulin-binding domain in Sema4D that regulates its exodomain shedding in platelets. Blood 121: 4221-4230, 2013.

4. Motani K and Kosako H: Activation of stimulator of interferon genes (STING) induces ADAM17-mediated shedding of the immune semaphorin SEMA4D. J Biol Chem 293: 7717-7726, 2018.

5. Ch'ng ES and Kumanogoh A: Roles of Sema4D and Plexin-B1 in tumor progression. Mol Cancer 9: 251, 2010. 
6. Nishide M, Nojima S, Ito D, Takamatsu H, Koyama S, Kang S, Kimura T, Morimoto K, Hosokawa T, Hayama Y, et al Semaphorin 4D inhibits neutrophil activation and is involved in the pathogenesis of neutrophil-mediated autoimmune vasculitis Ann Rheum Dis 76: 1440-1448, 2017

7. Xiao C, Luo Y, Zhang C, Zhu Z, Yang L, Qiao H, Fu M, Wang G, Yao $\mathrm{X}$ and Li W: Negative regulation of dendritic cell activation in psoriasis mediated via CD100-plexin-B2. J Pathol 250 409-419, 2020

8. Tsuda T, Nishide M, Maeda Y, Hayama Y, Koyama S, Nojima S, Takamatsu H, Okuzaki D, Morita T, Nakatani T, et al: Pathological and therapeutic implications of eosinophil-derived semaphorin 4D in eosinophilic chronic rhinosinusitis. J Allergy Clin Immunol 145: 843-854.e4, 2020.

9. Zhu L, Bergmeier W, Wu J, Jiang H, Stalker TJ, Cieslak M, Fan R, Boumsell L, Kumanogoh A, Kikutani H, et al: Regulated surface expression and shedding support a dual role for semaphorin 4D in platelet responses to vascular injury. Proc Natl Acad Sci USA 104: 1621-1626, 2007

10. Zhou H, Yang YH, Binmadi NO, Proia P and Basile JR: The hypoxia-inducible factor-responsive proteins semaphorin $4 \mathrm{D}$ and vascular endothelial growth factor promote tumor growth and angiogenesis in oral squamous cell carcinoma. Exp Cell Res 318 1685-1698, 2012.

11. Sierra JR, Corso S, Caione L, Cepero V, Conrotto P, Cignetti A, Piacibello W, Kumanogoh A, Kikutani H, Comoglio PM, et al: Tumor angiogenesis and progression are enhanced by Sema4D produced by tumor-associated macrophages. J Exp Med 205: $1673-1685,2008$.

12. Zhou H, Binmadi NO, Yang YH, Proia P and Basile JR: Semaphorin 4D cooperates with VEGF to promote angiogenesis and tumor progression. Angiogenesis 15: 391-407, 2012.

13. Ruan SS, Li RC, Han Q, Liu J, Li GL, Song YQ and Wu G: Expression and clinical significance of Semaphorin4D in non-small cell lung cancer and its impact on malignant behaviors of A549 lung cancer cells. J Huazhong Univ Sci Technolog Med Sci 34: 491-496, 2014

14. Liu H, Yang Y, Xiao J, Yang S, Liu Y, Kang W, Li X and Zhang F: Semaphorin 4D expression is associated with a poor clinical outcome in cervical cancer patients. Microvasc Res 93: $1-8,2014$

15. Chen Y, Zhang L, Lv R and Zhang WQ: Overexpression of Semaphorin4D indicates poor prognosis and prompts monocyte differentiation toward M2 macrophages in epithelial ovarian cancer. Asian Pac J Cancer Prev 14: 5883-5890, 2013.

16. Simon JM, Mokhtari K, Genestie C, Bissery A, Mazeron JJ and Jaillon P: Hypoxia-inducible factor lalpha (HIF-1 $\alpha$ ) and carbonic anhydrase IX (CA9) expressions in glioblastoma multiform to predict response to radiation therapy. J Clin Oncol 23 (Suppl 16): S1512, 2005

17. Ch'ng E, Tomita Y, Zhang B, He J, Hoshida Y, Qiu Y, Morii E, Nakamichi I, Hamada K, Ueda T and Aozasa K: Prognostic significance of CD100 expression in soft tissue sarcoma. Cancer 110: 164-172, 2007.

18. Kato S, Kubota K, Shimamura T, Shinohara Y, Kobayashi N, Watanabe S, Yoneda M, Inamori M, Nakamura F, Ishiguro H, et al: Semaphorin $4 \mathrm{D}$, a lymphocyte semaphorin, enhances tumor cell motility through binding its receptor, plexinB1, in pancreatic cancer. Cancer Sci 102: 2029-2037, 2011.

19. Soone J, Chen Y, Shustef EM and Scott GA: Sema4D, the ligand for Plexin B1, suppresses c-Met activation and migration and promotes melanocyte survival and growth. J Invest Dermatol 132: $1230-1238,2012$

20. Jiang H, Chen C, Sun Q, Wu J, Qiu L, Gao C, Liu W, Yang J, Jun $\mathrm{N}$ and Dong J: The role of semaphorin 4D in tumor development and angiogenesis in human breast cancer. Onco Targets Ther 9: 5737-5750, 2016.

21. Ding X, Qiu L, Zhang L, Xi J, Li D, Huang X, Zhao Y, Wang X and Sun Q: The role of semaphorin $4 \mathrm{D}$ as a potential biomarker for antiangiogenic therapy in colorectal cancer. Onco Targets Ther 9: 1189-1204, 2016.

22. Basile JR, Holmbeck K, Bugge TH and Gutkind JS: MT1-MMP controls tumor-induced angiogenesis through the release of semaphorin 4D. J Biol Chem 282: 6899-6905, 2007.

23. Granziero L, Circosta P, Scielzo C, Frisaldi E, Stella S, Geuna M, Giordano S, Ghia P and Caligaris-Cappio F: CD100/Plexin-B1 interactions sustain proliferation and survival of normal and leukemic CD5+ B lymphocytes. Blood 101: 1962-1969, 2003 .
24. Deaglio S, Vaisitti T, Bergui L, Bonello L, Horenstein AL, Tamagnone L, Boumsell L and Malavasi F: CD38 and CD100 lead a network of surface receptors relaying positive signals for B-CLL growth and survival. Blood 105: 3042-3050, 2005

25. Zhang C, Qiao H, Guo W, Liu Y, Yang L, Liu Y, Jin B, Fu M, Wang $\mathrm{G}$ and $\mathrm{Li} \mathrm{W}$ : CD100-plexin-B1 induces epithelialmesenchymal transition of head and neck squamous cell carcinoma and promotes metastasis. Cancer Lett 455: 1-13, 2019.

26. Clavijo PE,Friedman J, Robbins Y, Moore EC, Smith E,ZaudererM, Evans EE and Allen CT: Semaphorin4D inhibition improves response to immune-checkpoint blockade via attenuation of MDSC recruitment and function. Cancer Immunol Res 7: 282-291, 2019.

27. Zuazo-Gaztelu I, Pàez-Ribes M, Carrasco P, Martín L, Soler A, Martínez-Lozano M, Pons R, Llena J, Palomero L, Graupera M and Casanovas O: Antitumor effects of anti-Semaphorin 4D antibody unravel a novel proinvasive mechanism of vascular-targeting agents. Cancer Res 79: 5328-5341, 2019.

28. Brillantino C, Rossi E, Bifano D, Minelli R, Tamasi S, Mamone R, Bignardi E, Zeccolini R, Zeccolini M and Vallone G: An unusual onset of pediatric acute lymphoblastic leukemia. J Ultrasound: Apr 23, 2020 (Epub ahead of print).

29. Cheson BD, Cassileth PA, Head DR, Schiffer CA, Bennett JM, Bloomfield CD, Brunning $R$, Gale RP, Grever MR, Keating MJ, et al: Report of the national cancer institutesponsored workshop on definitions of diagnosis and response in acute myeloid leukemia. J Clin Oncol 8: 813-819, 1990.

30. Cortes JE and Kantarjian HM: Acute lymphoblastic leukemia. A comprehensive review with emphasis on biology and therapy. Cancer 76: 2393-2417, 1995.

31. Chung DC: The genetic basis of colorectal cancer: Insights into critical pathways of tumorigenesis. Gastroenterology 119: 854-865, 2000

32. Zhou W, Fu XQ, Liu J and Yu HG: RNAi knockdown of the Akt1 gene increases the chemosensitivity of gastric cancer cells to cisplatin both in vitro and in vivo. Regul Pept 176: 13-21, 2012.

33. Arboleda MJ, Lyons JF, Kabbinavar FF, Bray MR, Snow BE, Ayala R, Danino M, Karlan BY and Slamon DJ: Overexpression of AKT2/protein kinase Bbeta leads to up-regulation of beta1 integrins, increased invasion, and metastasis of human breast and ovarian cancer cells. Cancer Res 63: 196-206, 2003.

34. Lee MW, Kim DS, Lee JH, Lee BS, Lee SH, Jung HL, Sung KW, Kim HT, Yoo KH and Koo HH: Roles of AKT1 and AKT2 in non-small cell lung cancer cell survival, growth, and migration. Cancer Sci 102: 1822-1828, 2011.

35. Schlieman MG, Fahy BN, Ramsamooj R, Beckett L and Bold RJ: Incidence, mechanism and prognostic value of activated AKT in pancreas cancer. Br J Cancer 89: 2110-2115, 2003.

36. Fan DP, Zhang YM, Hu XC, Li JJ and Zhang W: Activation of AKT/ERK confers non-small cell lung cancer cells resistance to vinorelbine. Int J Clin Exp Patho 7: 134-143, 2013.

37. Lin Z, Zhang C, Zhang M, Xu D, Fang Y, Zhou Z, Chen X, Qin $N$ and Zhang $X$ : Targeting cadherin-17 inactivates Ras/Raf/MEK/ERK signaling and inhibits cell proliferation in gastric cancer. PLoS One 9: e85296, 2014.

38. Park JI: Growth arrest signaling of the Raf/MEK/ERK pathway in cancer. Front Biol (Beijing) 9: 95-103, 2014.

39. Fu S, Fan L, Pan X, Sun Y and Zhao H: Integrin $\alpha$ v promotes proliferation by activating ERK $1 / 2$ in the human lung cancer cell line A549. Mol Med Rep 11: 1266-1271, 2015.

40. Wei L, Li H, Tamagnone L and You H: Semaphorins and their receptors in hematological malignancies. Front Oncol 9: 382, 2019.

41. Basile JR, Gavard J and Gutkind JS: Plexin-B1 utilizes RhoA and Rho kinase to promote the integrin-dependent activation of Akt and ERK and endothelial cell motility. J Biol Chem 282: 34888-34895, 2007.

42. Engelman JA, Luo J and Cantley LC: The evolution of phosphatidylinositol 3-kinases as regulators of growth and metabolism. Nat Rev Genet 7: 606-619, 2006.

43. Tan F, Huang Y, Pei Q, Liu H, Pei H and Zhu H: Matrix stiffness mediates stemness characteristics via activating the Yes-associated protein in colorectal cancer cells. J Cell Biochem: Sep 14, 2018 (Epub ahead of print).

44. Jeong KY: Inhibiting focal adhesion kinase: A potential target for enhancing therapeutic efficacy in colorectal cancer therapy. World J Gastrointest Oncol 10: 290-292, 2018.

45. Zheng Q, Wang B, Gao J, Xin N, Wang W, Song X, Shao Y and Zhao C: CD155 knockdown promotes apoptosis via AKT/Bcl-2/Bax in colon cancer cells. J Cell Mol Med 22: 131-140, 2018. 
46. Ai X, Wu Y, Zhang W, Zhang Z, Jin G, Zhao J, Yu J, Lin Y, Zhang W, Liang H, et al: Targeting the ERK pathway reduces liver metastasis of Smad4-inactivated colorectal cancer. Cancer Biol Ther 14: 1059-1067, 2013.

47. Zinn RL, Gardner EE, Marchionni L, Murphy SC, Dobromilskaya I, Hann CL and Rudin CM: ERK phosphorylation is predictive of resistance to IGF-1R inhibition in small cell lung cancer. Mol Cancer Ther 12: 1131-1139, 2013.

48. Yan L, Gu H, Li J, Xu M, Liu T, Shen Y, Chen B and Zhang G: RKIP and 14-3-3e exert an opposite effect on human gastric cancer cells SGC7901 by regulating the ERK/MAPK pathway differently. Dig Dis Sci 58: 389-396, 2013.

49. Koyama T, Ogawara K, Kasamatsu A, Okamoto A, Kasama H, Minakawa Y, Shimada K, Yokoe H, Shiiba M, Tanzawa H and Uzawa K: ANGPTL3 is a novel biomarker as it activates ERK/MAPK pathway in oral cancer. Cancer Med 4: 759-769, 2015.
50. Lu Q, Dong N, Wang Q, Yi W, Wang Y, Zhang S, Gu H, Zhao X, Tang X, Jin B, et al: Increased levels of plasma soluble Sema4D in patients with heart failure. PLoS One 8: e64265, 2013.

51. Derakhshandeh R, Sanadhya S, Lee Han K, Chen H, Goloubeva O, Webb TJ and Younis RH: Semaphorin 4D in human head and neck cancer tissue and peripheral blood: A dense fibrotic peri-tumoral stromal phenotype. Oncotarget 9: 11126, 2018.

52. Yang YH, Buhamrah A, Schneider A, Lin YL, Zhou H, Bugshan A and Basile JR: Semaphorin 4D promotes skeletal metastasis in breast cancer. PLoS One 11: e0150151, 2016.

53. Tamagnone L and Franzolin G: Targeting semaphorin 4D in cancer: A look from different perspectives. Cancer Res 79: 5146-5148, 2019.

(i) (3) This work is licensed under a Creative Commons Attribution-NonCommercial-NoDerivatives 4.0 International (CC BY-NC-ND 4.0) License. 